\title{
Physical anhedonia in the acute phase of schizophrenia
} Vassilis P Kontaxakis*1, Costas T Kollias ${ }^{1}$, Beata J Havaki-Kontaxaki ${ }^{1}$, Maria M Margariti ${ }^{1}$, Sophia S Stamouli ${ }^{1}$, Eleni Petridou ${ }^{2}$ and George N Christodoulou ${ }^{3}$

\author{
Address: ${ }^{1}$ Department of Psychiatry, University of Athens, Eginition Hospital, 74 Vas. Sophias Ave, 11528 Athens, Greece, ${ }^{2}$ Department of Hygiene \\ and Epidemiology, University of Athens, 75 Micras Asias Ave, 11527, Goudi, Athens, Greece and ${ }^{3}$ Hellenic Centre for Mental Health and Research, \\ 58 Notara Ave, 10683 Athens, Greece \\ Email: Vassilis P Kontaxakis* - bkont@cc.uoa.gr; Costas T Kollias - kollias@med.uoa.gr; Beata J Havaki-Kontaxaki - bkont@cc.uoa.gr; \\ Maria M Margariti - mmarg@cc.uoa.gr; Sophia S Stamouli - sstamouli@med.uoa.gr; Eleni Petridou - epetridou@med.uoa.gr; \\ George N Christodoulou - gnchrist@compulink.gr \\ * Corresponding author
}

Published: 18 January 2006

Annals of General Psychiatry 2006, 5:I doi:10.1 186/1744-859X-5-1
Received: 12 October 2005

Accepted: 18 January 2006

This article is available from: http://www.annals-general-psychiatry.com/content/5/I/I

(c) 2006 Kontaxakis et al; licensee BioMed Central Ltd.

This is an Open Access article distributed under the terms of the Creative Commons Attribution License (http://creativecommons.org/licenses/by/2.0), which permits unrestricted use, distribution, and reproduction in any medium, provided the original work is properly cited.

\begin{abstract}
Background: The aim of the current study is to investigate the relationship between physical anhedonia and psychopathological parameters, pharmacological parameters or motor side-effects in a sample of inpatients with schizophrenia in an acute episode of their illness.

Method: Eighty one patients with schizophrenia, consecutively admitted, with an acute episode of their illness, at the Eginition Hospital, Department of Psychiatry, University of Athens, during a oneyear period were investigated regarding possible relationships between physical anhedonia, socialdemographic data and clinical parameters as well as motor side-effects, induced by antipsychotic agents. All patients were assessed using the Chapman Revised Physical Anhedonia Scale (RPAS), the Positive and Negative Syndrome Scale (PANSS), the Rating Scale for Extrapyramidal Side-Effects (EPSE), the Barnes Akathisia Rating Scale (BARS) and the Abnormal Involuntary Movement Scale (AIMS). Simple cross tabulations were initially employed. Subsequently, multiple regression analysis was performed.
\end{abstract}

Results: Both positive and negative symptoms were associated with physical anhedonia. A positive association between physical anhedonia and the non-paranoid sub-category of schizophrenia was also proved.

Conclusion: According to these results, it seems that in the acute phase of schizophrenia, physical anhedonia may be a contributing factor to patient's psychopathology.

\section{Background}

Anhedonia, a term first used by Ribot [1], describes the lack of interest and the withdrawal from all the usual and pleasant activities. Anhedonia has been described as a schizophrenic symptom by many authors, including
Bleuler and Kraepelin [2,3]. Rado [4,5] had suggested that anhedonia is a central, genetically transmitted defect both in overt schizophrenia and in compensated schizotypes. Meehl [6] has integrated Rado's views into a theory of neurological dysfunction in schizophrenia and proposed 
Table I: Mean patients' scores

\begin{tabular}{lll}
\hline Scale & Mean & $(\mathrm{SD})$ \\
\hline PAS & 19.10 & $( \pm 7.38)$ \\
PANSS - Positive symptoms & 18.47 & $( \pm 6.61)$ \\
PANSS - Negative symptoms & 20.20 & $( \pm 8.09)$ \\
PANSS - General psychopathology symptoms & 39.27 & $( \pm 11.30)$ \\
PANSS - Depression & 9.91 & $( \pm 2.94)$ \\
EPSE & 0.76 & $( \pm 0.58)$ \\
BARS & 0.30 & $( \pm 0.53)$ \\
AIMS & 0.12 & $( \pm 0.30)$ \\
\hline
\end{tabular}

PAS: Physical Anhedonia Scale, PANSS: Positive and Negative Syndrome Scale, EPSE: Rating Scale for Extrapyramidal Side-Effects, BARS: the Barnes Akathisia Rating Scale, AIMS: Abnormal Involuntary Movement Scale

that anhedonia is an enduring trait, a "cardinal symptom" preceding and possibly causing schizophrenia.

According to Chapman et al [7], there are two types of anhedonia, physical anhedonia and social anhedonia. Physical anhedonia which, usually, precedes the onset of the disease, represents a defect in the ability to experience physical pleasures, such as pleasures of eating, touching e. t. c., while social anhedonia represents a defect in the ability to experience interpersonal pleasure, such as pleasure of being with people, talking e. t. c.

There have been contradictory results regarding the association of anhedonia or its components to clinical parameters (i.e. negative symptoms, positive symptoms, depression) or to drug - treatment. Furthermore, there is a lack of studies regarding the relationship between physical anhedonia and psychopathological parameters in the acute phase of schizophrenia or between physical anhedonia and motor side - effects induced by antipsychotic agents.

The aim of the current study was to investigate the relationship between physical anhedonia and social-demographic, clinical parameters as well as motor side-effects in a sample of inpatients with schizophrenia in the acute phase of their illness.

\section{Methods \\ Subjects}

All patients with schizophrenia, consecutively admitted, with an acute episode of their illness, at the Eginition Hospital, Department of Psychiatry, University of Athens, during a one-year period were studied. Written informed consent was obtained from the subjects and their relatives.

The patients' diagnoses were made by two independent psychiatrists of similar level of education and experience according to DSM-IV criteria [8] and were reviewed on the day of discharge, taking into account all information collected during the inpatient period. Patients who presented with any other diagnosis on Axis I of DSM-IV, serious physical illness (especially neurological), substance abuse and mental retardation were excluded from the study.

Eighty one patients were finally diagnosed as suffering from schizophrenia. Fifty were male (62\%) and 31 female $(38 \%)$. Their mean age was $30.95( \pm 8.91)$ years, (age range 17 to 50 years). They had a mean of $12.6( \pm 2.7)$ years of education, a mean duration of illness of $6.9( \pm$ 7.6) years and a mean duration of hospitalisations of 0.4 $( \pm 0.8)$ years. Most of the patients were single $(85 \%)$. Patients were divided into the following subcategories: Paranoid type (57\%), undifferentiated type (20\%), disorganised type (13\%), residual type (10\%). 27 patients (34\%) were for the first time admitted while 54 (66\%) had more than one admissions (relapsers).

At the time of assessment, 65 patients (77\%) were receiving antipsychotic drugs. Out of a total of 81 patients on antipsychotic drugs, $62 \%$ were receiving conventional antipsychotics, $27 \%$ used atypical antipsychotics as monotherapy and $12 \%$ used conventional plus atypical antipsychotics in combination. Eleven patients (13.6\%) were consuming antidepressants, 41 (50.6\%) anxiolytics, 2 (2.5\%) mood stabilizers and 45 (55.6\%) anti-parkinsonian agents.

\section{Clinical assessments}

All patients were assessed using the following scales: the Chapman Revised Physical Anhedonia Scale [RPAS] (9), the Positive and Negative Syndrome Scale (PANSS) $[10,11]$, the Rating Scale for Extrapyramidal Side-Effects (EPSE) [12], the Barnes Akathisia Rating Scale (BARS) [13] and the Abnormal Involuntary Movement Scale (AIMS) $[14,15]$. The severity of depression was estimated using the depression cluster score of the PANSS (items $\mathrm{G} 1+\mathrm{G} 2+\mathrm{G} 3+\mathrm{G} 6)[16,17]$.

Means and standard deviations of the main variables are shown in table 1.

Subjects were assessed during the first week of their hospitalisation by three independent psychiatrists-raters. The first rater assessed the patients using the RPAS and the AIMS, the second using the PANSS and the EPSE and the third using the BARS. Information from the patient's history, concerning social-demographic and clinical parameters was recorded in a pre-coded interview form. The antipsychotic agents dosage was estimated in chlorpromazine equivalents $[18,19]$. 
Table 2: Distribution of 8 I patients with schizophrenia by sociodemographic and clinical variables and the percentages of the physical anhedonia score calculated for each gender

\begin{tabular}{|c|c|c|c|c|c|c|c|}
\hline \multirow[t]{2}{*}{ Variable } & \multicolumn{6}{|c|}{ physical anhedonia score thirtiles } & \multirow[t]{2}{*}{$\mathrm{p}=$} \\
\hline & st & $(\%)$ & $2^{\text {nd }}$ & $(\%)$ & $3^{\text {rd }}$ & (\%) & \\
\hline \multicolumn{8}{|l|}{ Gender } \\
\hline Male & 17 & 34.0 & 15 & 30.0 & 18 & 36.0 & 0.64 \\
\hline Female & 10 & 32.3 & II & 35.6 & 10 & 32.3 & \\
\hline \multicolumn{8}{|l|}{ Age (years) } \\
\hline$<25$ years & 10 & 43.5 & 10 & 43.5 & 3 & 13.0 & 0.09 \\
\hline $25-34$ & 9 & 29.0 & 8 & 25.8 & 14 & 45.2 & \\
\hline$>35$ & 8 & 29.6 & 8 & 29.6 & 11 & 40.8 & \\
\hline \multicolumn{8}{|c|}{ Education (years) } \\
\hline$\leq 12$ & 13 & 28.9 & 15 & 33.3 & 17 & 37.8 & 0.35 \\
\hline$>13$ & 14 & 38.8 & 11 & 30.6 & II & 30.6 & \\
\hline \multicolumn{8}{|l|}{ Family status } \\
\hline Unmarried & 19 & 27.5 & 26 & 37.7 & 24 & 34.8 & 0.12 \\
\hline Other & 8 & 66.7 & 0 & 0.0 & 4 & 33.3 & \\
\hline \multicolumn{8}{|c|}{ Diagnostic sub-category } \\
\hline Paranoid & 22 & 47.8 & 13 & 28.3 & II & 23.9 & $0.002^{*}$ \\
\hline Other & 5 & 14.3 & 13 & 37.1 & 17 & 48.6 & \\
\hline \multicolumn{8}{|c|}{ PANSS-positive subscale score } \\
\hline$\leq 19$ & 20 & 42.6 & 15 & 31.9 & 12 & 25.5 & $0.02 *$ \\
\hline$>20$ & 7 & 20.6 & 11 & 32.3 & 16 & 47.1 & \\
\hline \multicolumn{8}{|c|}{ PANSS-negative subscale score } \\
\hline$\leq 19$ & 17 & 40.5 & 15 & 35.7 & 10 & 23.8 & $0.04 *$ \\
\hline$>20$ & 10 & 25.6 & 11 & 28.2 & 18 & 46.2 & \\
\hline
\end{tabular}

*statistically significant difference, Chi - square tests

\section{Statistical analyses}

The SPSS 8.0 was used for the statistical analysis. Since there is no cut-off point for schizophrenia, dividing anhedonic subjects from non-anhedonic ones, physical anhedonia scores were divided in thirtiles according to the ratings in rPAS ( $1^{\text {st }}$ thirtile: $<15$ and $<14,2^{\text {nd }}$ thirtile: $16-$ 22 and 15-21, $3^{\text {rd }}$ thirtile: $>23$ and $>22$ for men and women respectively). Then, possible correlations were explored between: physical anhedonia and social-demographic parameters (i.e. sex, age, family status e.t.c.), clinical parameters (i.e. diagnostic sub-category) and psychopathological parameters derived from the aforementioned scales and their subscales used. Simple cross tabulations were initially employed. Of all the parameters cross-tabulated with physical anhedonia, statistically significant differences between subjects with lower anhedonia scores and subjects with higher anhedonia scores were found only for the PANSS positive sub-scale score, the PANSS negative sub-scale score and the dianostic sub-category parameter. Subsequently, multiple regression analysis was performed, using as predictor core model the following variables: gender, age, family status, diagnosis and years of education and diagnostic sub-category. Alternative introduced clinical standard variables to the core model were the PANSS positive sub-scale score and the PANSS negative sub-scale score. The physical anhedonia score was the dependent variable.

\section{Results}

Tables 2 shows the distribution of the sample crossclassified by sociodemographic, clinical variables and the physical anhedonia score thirtiles. The severity of physical anhedonia was significantly related to the diagnostic subcategory of non-paranoid schizophrenia, to the positive symptoms score and to the negative symptoms score of the PANSS.

Table 3 shows the associations of physical anhedonia scores with the core model variables and the multiple regression analysis results. There were statistically significant associations of physical anhedonia scores with alternative clinical variables which were introduced to the core model. Single patients tended to have higher scores of physical anhedonia than others $(\mathrm{p}=0.05)$. Older patients tended to score higher on physical anhedonia $(\mathrm{p}=0.05)$. Patients with paranoid schizophrenia had lower scores of physical anhedonia than non-paranoid patients with schizophrenia $(\mathrm{p}=0.004)$. Both positive symptoms score and negative symptoms score were positive predictors of physical anhedonia $(\mathrm{P}=0.03$ and $\mathrm{P}=0.01$, respectively).

\section{Discussion}

This is the first study searching simultaneously for possible association between physical anhedonia and positive symptoms, negative symptoms or general psychopathol- 
Table 3: Multiple regression-derived partial regression coefficients (b), standard errors (SE) and corresponding p-values for prediction of physical anhedonia from core model variables and clinical standard variables

\begin{tabular}{|c|c|c|c|c|}
\hline Variable & Category & B & SE & $p=$ \\
\hline \multicolumn{5}{|l|}{ Core model } \\
\hline \multicolumn{5}{|l|}{ Gender } \\
\hline & Male & & & \\
\hline & Female & -0.41 & 1.63 & 0.81 \\
\hline \multicolumn{5}{|l|}{ Age (years) } \\
\hline & $<25$ & & & \\
\hline & $25-34$ & & & \\
\hline & $>35$ & 1.99 & 1.01 & 0.05 \\
\hline \multicolumn{5}{|l|}{ Education (years) } \\
\hline & $\leq 12$ years & & & \\
\hline & $>13$ & -2.13 & 1.55 & 0.17 \\
\hline \multicolumn{5}{|l|}{ Family Status } \\
\hline & Unmarried & & & \\
\hline & Other & -4.69 & 2.31 & 0.05 \\
\hline \multicolumn{5}{|l|}{ Diagnostic sub-category } \\
\hline & Paranoid & & & \\
\hline & Other & 4.63 & 1.57 & $0.004 *$ \\
\hline \multicolumn{5}{|c|}{$\begin{array}{l}\text { Alternative introduced variables to the core model } \\
\text { Model I }\end{array}$} \\
\hline \multirow{2}{*}{ PANSS-positive subscale score } & $\leq 19$ & & & \\
\hline & $>20$ & 3.34 & 1.54 & $0.03 *$ \\
\hline \multicolumn{5}{|l|}{ Model 2} \\
\hline \multirow[t]{2}{*}{ PANSS-negative subscale score } & $\leq 19$ & & & \\
\hline & $>20$ & 3.89 & 1.53 & $0.01 *$ \\
\hline
\end{tabular}

* statistically significant difference

ogy symptoms as well as motor side effects induced by antipsychotic agents in inpatients with schizophrenia in the acute phase of their illness.

Starting with, we should mention several limitations of our study. First, we used a mixed population of patients with schizophrenia regarding their medication status. Second, there was a lack of a specific scale measuring depression in schizophrenia. Third, we studied patients in the acute phase of their illness. Hence, it was possible that positive symptoms may dominate and overlap the clinical manifestation of the disease.

According to our results, the severity of physical anhedonia was associated with the severity of both positive and negative symptoms. Also, a positive association between physical anhedonia and the sub-category of non-paranoid schizophrenia was presented. However, the severity of physical anhedonia was found to be independent to depression, to general psychopathology symptoms or motor side-effects induced by antipsychotic agents.

Regarding the relationship of physical anhedonia and negative symptoms the results are in line with those by Loas et al [20] and Kirkpatrick et al [21] who have demon- strated that physical anhedonia and deficit symptoms, which are described as enduring negative symptoms, were significantly related. Yet, Herbener et al [22] found that the PAS score of patients with schizophrenia was significantly correlated to negative symptoms, estimated by the SADS structured interview, at the 4.5 year follow up assessment. However, contrary to our results, Loas et al [23] found that physical anhedonia in chronic patients with schizophrenia was not significantly related to negative symptoms, estimated by both the PANSS and the BPRS. Other studies, as well, have reported an absence of significant correlation between physical anhedonia and negative symptoms as measured by the Positive and Negative Symptoms Scale (PANSS), the Brief Psychiatric Rating Scale (BPRS), or the SANS [24-26].

Regarding the relationship of physical anhedonia and positive symptoms, contrary to our results, Herbener et al [22] found that the PAS score of patients with schizophrenia was not correlated to florid psychotic symptoms, estimated by the SADS, over a 10 - year follow up period. Also, Loas et al [23] found that physical anhedonia in chronic patients with schizophrenia was not significantly related to positive symptoms, estimated by both the PANSS and the BPRS.

Regarding the relationship of physical anhedonia and the non-paranoid sub-type of schizophrenia, contrary to our results, Schunck et al [27] did not find a correlation between the PAS score and the schizophrenia sub-type in a sample of out-patients with schizophrenia.

The observation that physical anhedonia is independent of depression in schizophrenia seems to be consistent with the findings of Herbener et al [22]. They used a subscale of the SADS to estimate depression. Also, Loas et al [23] have found that physical anhedonia in chronic patients with schizophrenia was not significantly related to depression, estimated by the Beck Depression Inventory.

Regarding the relationship of physical anhedonia and general psychopatology symptoms, similar to our results are the findings of Loas et al [23] who have found that physical anhedonia in chronic patients with schizophrenia was not significantly related to general psychopathology symptoms, estimated by both the PANSS and the BPRS.

We did not find any studies exploring the the relationship between physical anhedonia and motor side effects induced by antipsychotic agents. 


\section{Conclusion}

According to our results, it seems that in the acute phase of schizophrenia, physical anhedonia may be a component of patient's psychopathology. Further studies to elucidate the nature of physical anhedonia and its relationship to various phases of the schizophrenic disorder are needed.

\section{References}

I. Ribot TH: The psychology of emotions London: Scott; 1897.

2. Bleuler E: Originally Published, I9II. In Dementia praecox or the group of schizophrenias Edited by: Tranl, Zinkin J. New York: International Universities Press; 1950.

3. Kraepelin E: Originally Published, 1913. In Dementia praecox and paraphrenia Edited by: Transl, Baclay BM. Edinburg E \& S Livingstone; 1919.

4. Rado S: Psychoanalysis of Behaviour; Collected Papers New York: Grune and Stratton; 1956.

5. Rado S: Psychoanalysis of Behaviour; Collected Papers. 1956-196I Volume 2. New York: Grune and Stratton; 1962.

6. Meehl PE: Schizotaxia, schizotypy, schizophrenia. American Psychologist 1962, I 7:827-838.

7. Chapman LJ, Chapman JP, Raulin ML: Scales for physical and social anhedonia. J Abn Psychology 1976, 85:374-382.

8. American Psychiatric Association: Diagnostic and Statistical Manual of Mental Disorders Fourth edition. Washington DC; 1994.

9. Chapman LJ, Chapman JP: Revised Physical Anhedonia Scale. Unpublished test 1978.

10. Kay SR, Fiszbein A, Opler LA: The positive and negative syndrome scale (PANSS) for schizophrenia. Schizophr Bull 1987, I 3:26|-276.

II. Lykouras L, Botsis A, Oulis P: Positive and Negative Syndrome Scale. Translation - Validity - Reliability (in Greek) Athens: Tsiveriotis eds; 1997.

12. Simpson $\mathrm{CM}$, Angus ]: A rating scale for extrapyramidal effects. Acta Psychiatr Scand 1970, 2 I 2(Suppl I): I I- 19.

13. Barnes TRE: A rating scale for drug-induced akathisia. Br J Psychiatry 1989, 154:672-676.

14. Munetz MR, Benjamin S: How to examine patients using the Abnormal Involuntary Movement Scale. Hosp Comm Psychiatry I998, 39(I I): I I 72-II77.

15. Guy W: ECDEU Assessment Manual for Psychopharmacology, revised ed Washington DC: US Department of Health, Education and Welfare; 1976.

16. Kay SR, Sevy S: Pyramidal model of schizophrenia. Schizophr Bull 1990, 16:537-545.

17. Kay SR: Positive and Negative syndromes in schizophrenia: Assessment and research New York: Brunner/Mazel; 1991.

18. Kalyna Z: Clinical Handbook of Psychotropic drugs Fifth Revised edition. Seattle: Hogrefe \& Huber Publishers; 1995.

19. Casey PE: Side-effect profiles of new antipsychotic agents. J Clin Psychiatry 1996, 57(SuppI I I):40-45.

20. Loas G, Noisette C, Legrand A, Boyer P: Anhedonia, depression and the deficit syndrome of schizophrenia. Acta Psychitr Scand 1996, 94:477-479.

21. Kirkpatrick B, Buchanan RW: Anhedonia and the deficit syndrome in schizophrenia. Psychiatry Res 1990, 3 I:25-30.

22. Herbener $E$, Harrow $M$ : The course of anhedonia during $\mathbf{I} 0$ years of schizophrenic illness. J Abn Psychology 2002, I I I(2):237-248.

23. Loas G, Boyer P, Legrand A: Anhedonia and negative symptomatology in chronic schizophrenia. Compr Psychiatry 1996, 37(I):5-II.

24. Loas G, Noisette C, Legrand A, Boyer P: Is anhedonia a specific dimension in chronic schizophrenia? Schizoph Bull 2000, 26(2):495-506.

25. Berenbaum H, Oltmanns TF: Emotional experience and expression in schizophrenia and depression. J Abn Psychology 1992, I 0 l:37-44.

26. Blanchard J, Bellack AS, Mueser KT: Affective and social-behavioral correlates of physical and social anhedonia in schizophrenia. J Abn Psychology 1994, 103:719-728.
27. Schuck J, Leventhal D, Rothstein H, Irizary V: Physical anhedonia and schizophrenia. J Abn Psychology 1984, 93(3):342-344.
Publish with Biomed Central and every scientist can read your work free of charge

"BioMed Central will be the most significant development for disseminating the results of biomedical research in our lifetime. " Sir Paul Nurse, Cancer Research UK

Your research papers will be:

- available free of charge to the entire biomedical community

- peer reviewed and published immediately upon acceptance

- cited in PubMed and archived on PubMed Central

- yours - you keep the copyright
BioMedcentral 